\title{
Technical note: Effects of iron(II) on fluorescence properties of dissolved organic matter at circumneutral pH
}

\author{
Kun Jia $^{1, \mathrm{a}}$, Cara C. M. Manning ${ }^{1, \mathrm{~b}}$, Ashlee Jollymore ${ }^{2, \mathrm{c}}$, and Roger D. Beckie ${ }^{1}$ \\ ${ }^{1}$ The University of British Columbia, Department of Earth, Ocean and Atmospheric Sciences, Vancouver, BC, Canada \\ ${ }^{2}$ The University of British Columbia, Institute for Resources, Environment and Sustainability, Vancouver, BC, Canada \\ a currently at: AECOM Canada, Burnaby, BC, Canada \\ b currently at: Plymouth Marine Laboratory, Plymouth, UK \\ ${ }^{c}$ currently at: Province of British Columbia, Ministry of Forest, Lands, Natural Resource Operations and Rural Development, \\ Victoria, BC, Canada
}

Correspondence: Kun Jia (kun418@gmail.com) and Roger D. Beckie (rbeckie@eoas.ubc.ca)

Received: 1 April 2020 - Discussion started: 11 May 2020

Revised: 9 August 2021 - Accepted: 10 August 2021 - Published: 15 September 2021

\begin{abstract}
Modern fluorescence spectroscopy methods, including excitation-emission matrix (EEM) spectra parsed using parallel factor analysis (PARAFAC) statistical approaches, are widely used to characterize dissolved organic matter (DOM) pools. The effect of soluble reduced iron, $\mathrm{Fe}(\mathrm{II})$, on EEM spectra can be significant but is difficult to quantitatively assign. In this study, we examine the effects of $\mathrm{Fe}(\mathrm{II})$ on the EEM spectra of groundwater samples from an anaerobic deltaic aquifer containing up to $300 \mathrm{mg} \mathrm{L}^{-1} \mathrm{Fe}(\mathrm{II})$, located a few kilometres from the ocean and adjacent to the Fraser River in Richmond, British Columbia, Canada. We added varying quantities of $\mathrm{Fe}(\mathrm{II})$ into groundwater samples to evaluate $\mathrm{Fe}$ (II)-DOM interactions. Both the overall fluorescence intensity and the intensity of the primary peak, a humic-like substance at excitation and emission wavelengths of 239 and $441-450 \mathrm{~nm}$ (peak A), respectively, decreased by approximately $60 \%$ as $\mathrm{Fe}(\mathrm{II})$ concentration increased from 1 to $306 \mathrm{mg} \mathrm{L}^{-1}$. Furthermore, the quenching effect was nonlinear and proportionally stronger at $\mathrm{Fe}(\mathrm{II})$ concentrations below $100 \mathrm{mgL}^{-1}$. This nonlinear relationship suggests a static quenching mechanism. In addition, DOM fluorescence indices are substantially influenced by the Fe(II) concentration. With increasing Fe(II), the fluorescence index (FI) shifts to higher values, the humidification index (HIX) shifts to lower values, and the freshness index (FrI) shifts to higher values. Nevertheless, the 13-component PARAFAC model showed that the component distribution was relatively insensitive to $\mathrm{Fe}(\mathrm{II})$ concentration; thus, PARAFAC may be a reli-
\end{abstract}

able method for obtaining information about the DOM composition and its redox status in Fe(II)-rich waters. By characterizing the impacts of up to $300 \mathrm{mg} \mathrm{L}^{-1} \mathrm{Fe}$ (II) on EEMs using groundwater from an aquifer which contains similar $\mathrm{Fe}(\mathrm{II})$ concentrations, we advance previous work which characterized impacts of lower Fe(II) concentrations (less than $2 \mathrm{mg} \mathrm{L}^{-1}$ ) on EEMs.

\section{Introduction}

Fluorescence spectroscopy has been widely used to characterize the properties of dissolved organic matter as it is highly sensitive to the structures and functional chemistry of aquatic organic matter (Baker and Spencer, 2004; Fellman et al., 2010; Helms et al., 2008; Stedmon and Bro, 2008; Weishaar et al., 2003). In this method, light at a known wavelength (the excitation wavelength) is passed through a sample, and the absorbance at that frequency and fluorescence (emission) at other frequencies is measured. Such spectra can be used to derive commonly utilized fluorescence indices that correlate to specific forms of organic matter (Aiken, 2014; Coble et al., 2014; Hudson et al., 2007; Murphy et al., 2013). These indices include the fluorescence index (FI), which is calculated as the ratio between the emission at $470 \mathrm{~nm}$ to that at $530 \mathrm{~nm}$ at an excitation wavelength of $370 \mathrm{~nm}$ and relates to the concentration of aromatic, microbially derived ligninlike organic matter (McKnight et al., 2001). An excitation- 
emission matrix (EEM) is prepared by systematically repeating the measurements at a range of different excitation and emission wavelengths. These measurements are highly sensitive to the structures and functional chemistry of aquatic organic matter, which determine the unique pattern of peaks present within the EEM spectra (Aiken, 2014; Coble, 1996; Coble et al., 2014; Fellman et al., 2010). Due to the complexity of the EEM spectra obtained from each unique sample, a number of statistical methods have been used to decompose EEM spectra and relate emission patterns to functional chemistry of organic matter within a sample. Parallel factor analysis (PARAFAC) is a commonly utilized statistical means of compartmentalizing EEM spectra into discrete peaks that may then be compared to broad organic matter classes (Bro, 1997; Chen et al., 2010; Jaffé et al., 2014; Murphy et al., 2013; Stedmon and Bro, 2008).

It is well accepted that dissolved organic matter (DOM) fluorescence is quenched or enhanced by interactions with metal ions, including Fe(III) (Ohno et al., 2008; Poulin et al., 2014; Pullin et al., 2007; Senesi, 1990; Shen et al., 2020), $\mathrm{Fe}(\mathrm{II})$ (Poulin et al., 2014), Al(III) (Ohno et al., 2008), Cu(II) (Senesi, 1990; Shen et al., 2020), and Hg(II) (Senesi, 1990). $\mathrm{Fe}$ (III) is recognized as an important source of interference for fluorescence measurements (Ohno et al., 2008; Pullin et al., 2007). Previous studies have reported a significant quenching effect caused by the binding of $\mathrm{Fe}(\mathrm{III})$ to organic ligands. A possible mechanism that may account for quenching is iron(II)-DOM complexation occurring at the fluorescent sites (Senesi, 1990; Rue and Bruland, 1995). Such complexes can efficiently decrease the fluorescence intensity of the fluorophore. Furthermore, the degree of quenching varies among different organic matter compounds, which increases the complexity and uncertainty in characterizing and predicting the iron-binding effect across a range of DOM types (Ohno et al., 2008). However, limited research has focused on the quenching effect of $\mathrm{Fe}(\mathrm{II})$ interference in anoxic groundwater, where reducing conditions are present. Poulin et al. (2014) first demonstrated that Fe(II) complexation with DOM decreases fluorescence intensity. Their experiments were only designed to characterize the Fe(II) quenching effect for surface water with moderately elevated DOM concentrations ( 2.3 to $5.0 \mathrm{mg} \mathrm{L}^{-1}$ ) under low $\mathrm{Fe}$ (II) concentrations $\left(0-1.5 \mathrm{mg} \mathrm{L}^{-1}\right)$. To our knowledge, the extent of fluorescence quenching in groundwater with higher Fe(II) concentrations is not known.

The fluorescence quenching effect in Fe(II)-rich groundwater is still poorly understood and warrants further investigation, given the prevalence of high DOM and $\mathrm{Fe}(\mathrm{II})$ in groundwater in deltaic sediments (Bolton and Beckie, 2011) and sites contaminated with organics, e.g. from landfills or fuel spills (van Breukelen and Griffioen, 2004; Christensen et al., 2001; Heron et al., 1994). In most instances, these high-Fe(II) groundwaters are found when the oxidation of organic matter is coupled to solid-phase Fe(III) reduction, dissolving $\mathrm{Fe}(\mathrm{II})$ into groundwater at circumneutral $\mathrm{pH}$. For example, $1.5-10 \mathrm{mg} \mathrm{L}^{-1} \mathrm{Fe}(\mathrm{II})$ in groundwater is commonly observed in the organic-rich groundwaters of the Bengal Basin (Harvey et al., 2002), and up to $90 \mathrm{mg} \mathrm{L}^{-1} \mathrm{Fe}$ (II) has been observed in landfill leachate in the Netherlands (van Breukelen and Griffioen, 2004).

The objective of this study was to assess the influence of high concentrations of $\mathrm{Fe}$ (II) on the fluorescence properties of DOM by titrating up to $306 \mathrm{mg} \mathrm{L}^{-1}(5.4 \mathrm{mM}) \mathrm{Fe}$ (II) into groundwater collected from a deltaic aquifer in Richmond, British Columbia, Canada. This groundwater is representative of groundwater found in diagenetically immature, organic-rich deltaic sediments, where $\mathrm{Fe}(\mathrm{II})$ concentrations can reach up to $300 \mathrm{mg} \mathrm{L}^{-1}$ (Bolton and Beckie, 2011; Jia, 2015). The biogeochemistry of groundwater at this site and an analysis of the origin of the extraordinarily high Fe(II) concentrations are described in Jia (2015). In this study, we identified the degree of quenching at different $\mathrm{Fe}$ (II) concentrations (from 1 to $306 \mathrm{mg} \mathrm{L}^{-1}$ ) based on the excitation-emission matrix (EEM) regions and peaks. We fit the EEM spectra to a previously derived 13-component PARAFAC model (Cory and McKnight, 2005) and calculated commonly used fluorescence indices to quantify DOM fluorescence properties as a function of $\mathrm{Fe}(\mathrm{II})$ concentration. This study provides a detailed characterization of the impact of changing $\mathrm{Fe}(\mathrm{II})$ concentrations on DOM fluorescence.

\section{Deltaic groundwater stock solution}

We collected representative deltaic groundwaters from what is known as the Kidd 2 site, located adjacent to the Fraser River a few kilometres upstream from its outlet to the ocean, near Vancouver, Canada ( $49^{\circ} 11^{\prime} 53.34^{\prime \prime} \mathrm{N}, 123^{\circ} 6^{\prime} 53.25^{\prime \prime} \mathrm{W}$, Fig. 1), where a near-surface sandy aquifer is found between 5 and $22 \mathrm{~m}$ below ground surface (Jia, 2015; Bolton and Beckie, 2011). In the anaerobic deltaic aquifer, Fe(II) is released to groundwater by oxidation of dissolved organic matter (DOM) in a process that is affected by the circulation of saline ocean water. At the site, denser, saline ocean water enters the aquifer in the hyporheic zone at the river bottom, flows inland along the base of the aquifer to a maximum distance of approximately $500 \mathrm{~m}$ inland where it overturns and flows back towards the river under a regional hydraulic gradient from freshwater recharged inland (Neilson-Welch and Smith, 2001), forming a wedge of saline water in the aquifer (Fig. 2). Along the flow path, the saline water mixes with fresh groundwater. The saline-freshwater mixture eventually discharges to the river at the top of the saline wedge. Two mixing zones can be identified along the saline wedge: at the bottom of the wedge, freshwater from the lower confining silt flows up into the overlying sandy aquifer as the saline water flows inland (the "lower mixing zone") and, at the top of the wedge, terrestrial recharge from inland flows on top of the saline water as it flows back to the river (the "upper mixing zone"). High concentrations of Fe(II) are observed 


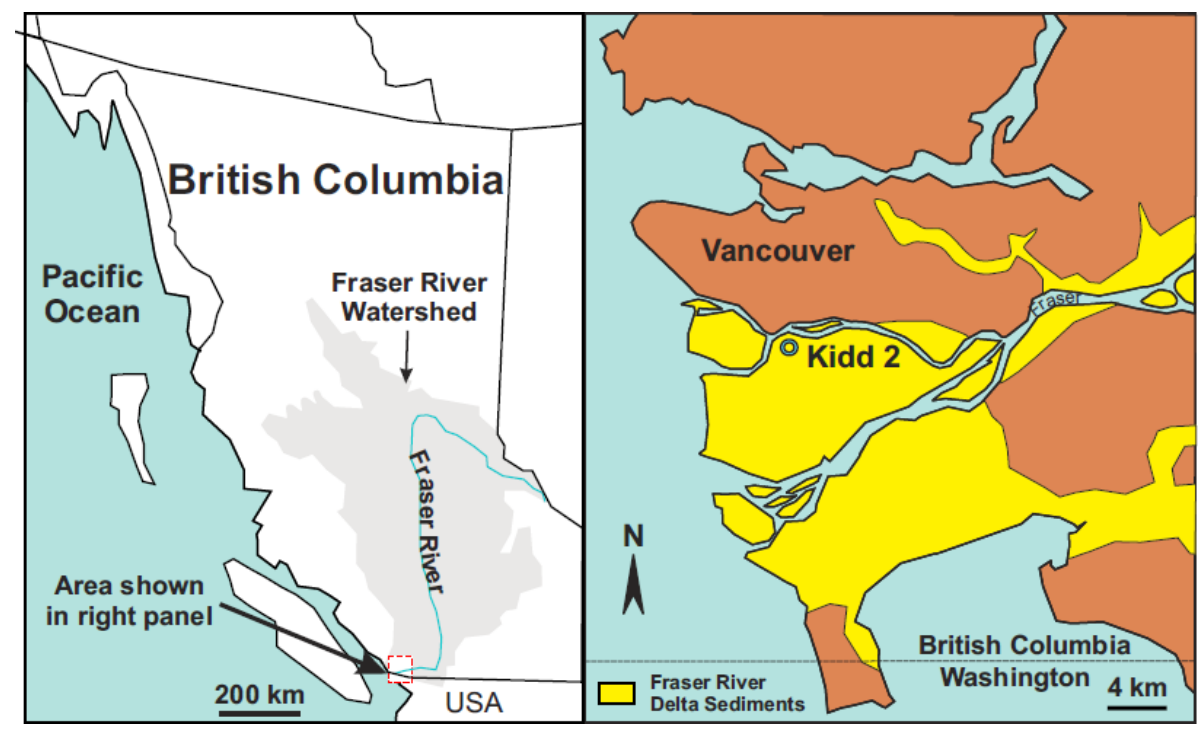

Figure 1. The Kidd 2 site is located in the Fraser River delta in southwest British Columbia.

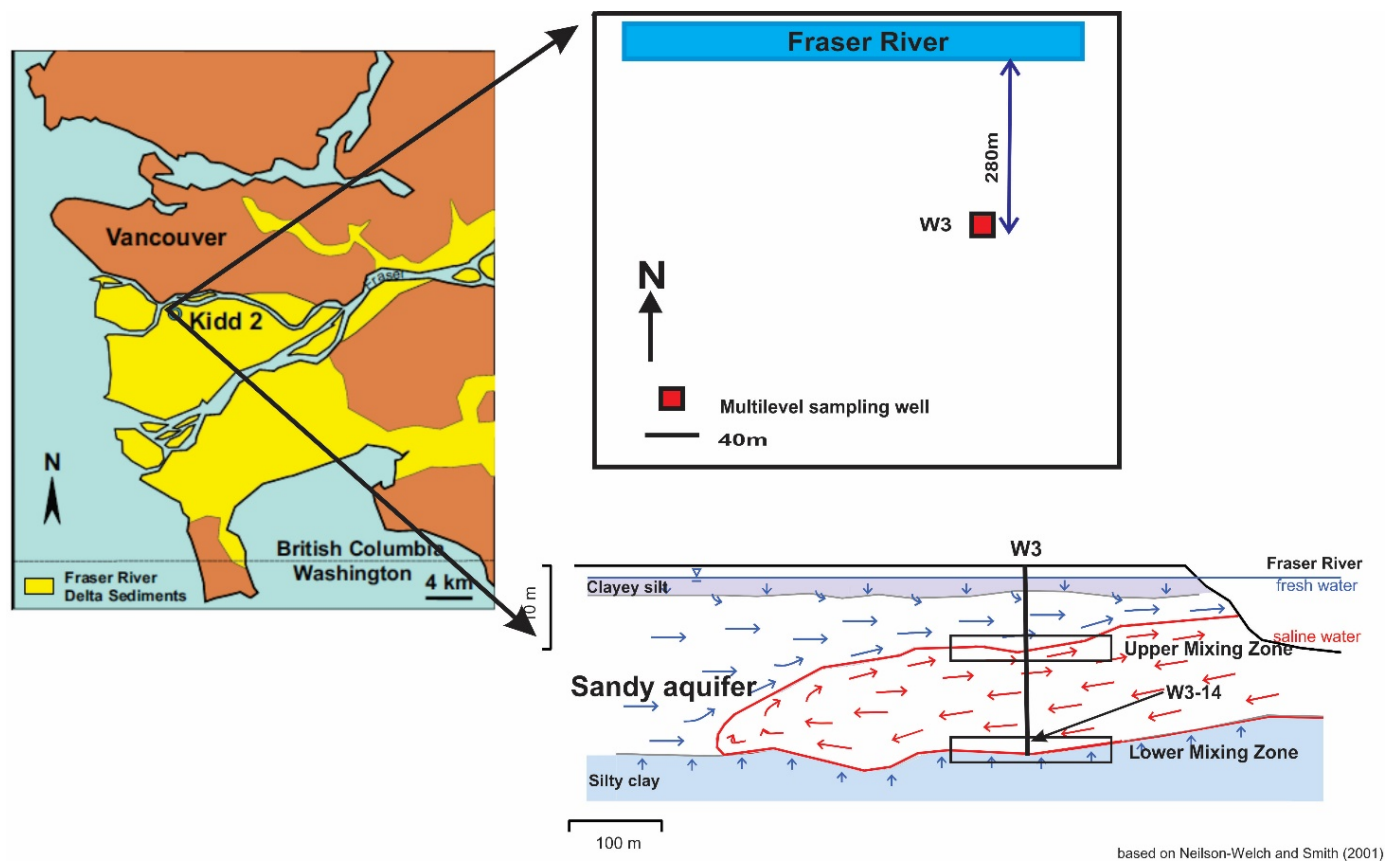

Figure 2. Plan view of the W3 well location and cross section of the saline wedge, after Neilson-Welch and Smith (2001).

along the circulation flow path, especially in the upper mixing zone, where pore water Fe(II) concentrations peak above $300 \mathrm{mg} \mathrm{L}^{-1}$ (5.4 mM) (Fig. 2) (Jia, 2015).

\section{Methodology}

\subsection{Sample collection}

For the measurements in this study, we collected a single stock solution of representative natural DOM-containing groundwater, to which we added (titrated) increasing concentrations of $\mathrm{Fe}(\mathrm{II})$. We selected groundwater from W3-14 (lower mixing zone) at a depth of $20.03 \mathrm{~m}$ as the DOMcontaining stock solution as it had the lowest $\mathrm{Fe}(\mathrm{II})$ concentration $\left(1.3 \mathrm{mg} \mathrm{L}^{-1}\right)$ at the Kidd 2 site (Jia, 2015), allowing us to explore a large range of $\mathrm{Fe}(\mathrm{II})$ concentrations. The multilevel sampling port consisted of a $0.635 \mathrm{~cm}$ inner diameter low-density polyethylene tube with a $5 \mathrm{~cm}$ fibreglass-mesh screen (Neilson-Welch and Smith, 2001). Three tubing volumes of groundwater were purged with a peristaltic pump 
while $\mathrm{pH}$ was monitored using an OAKTON ${ }^{\mathrm{TM}} \mathrm{pH} / \mathrm{mV} /{ }^{\circ} \mathrm{C}$ meter in a sealed flow-through cell to prevent degassing. The $\mathrm{pH}$ and temperature stabilized at 7.44 and $11^{\circ} \mathrm{C}$, respectively. The groundwater was filtered through $0.45 \mu \mathrm{m}$ cellulose filters and then stored in a $1 \mathrm{~L}$ amber glass bottle with a Teflon-lined plastic cap, without acidification. The bottle was filled with no headspace and duct tape was used to further seal the sample and minimize the oxidation of Fe(II). The collected $1 \mathrm{~L}$ stock solution was refrigerated at $4{ }^{\circ} \mathrm{C}$ until fluorescence analysis (within $\sim 14 \mathrm{~d}$ ). Although some degradation of the DOM may have occurred during the holding period, this would not significantly affect our conclusions as our intention was to determine how $\mathrm{Fe}$ (II) addition affects the fluorescence properties of DOM rather than to characterize the properties of DOM at the Kidd 2 site. The stock solution DOM concentration of $10.7 \mathrm{mg} \mathrm{L}^{-1}$ was measured using high-temperature combustion with a $\mathrm{HACH}^{\mathrm{TM}} \mathrm{IL} 550$ TOC-TN analyser (detection limit $1 \mathrm{mgL}^{-1}$ ) at the Environmental Engineering Laboratory in The University of British Columbia's Department of Civil Engineering.

\section{2 $\mathrm{Fe}$ (II) addition experiment and concentration determination}

Experimental solutions were prepared from the stock DOM solution in an anaerobic glovebox (Coy Labs, MI, USA), filled with an $\mathrm{N}_{2} / \mathrm{H}_{2}$ mixture ( $95 \%$ of $\mathrm{N}_{2}$ and $5 \%$ of $\mathrm{H}_{2}$ ) with a palladium catalyst inside the chamber, which maintains gaseous $\mathrm{O}_{2}$ levels of less than $5 \mathrm{ppm}$. The stock DOM solution was de-aerated in the glovebox by purging with pure $\mathrm{N}_{2}$ for $30 \mathrm{~min}$. The sample addition experiments used glass cuvettes that were acid-washed with $10 \% \mathrm{HNO}_{3}$ and rinsed with deionized, distilled water.

As the highest observed $\mathrm{Fe}$ (II) concentration in the groundwater at the Kidd 2 site was approximately $300 \mathrm{mg} \mathrm{L}^{-1}$ (Jia, 2015), the Fe(II) addition experiment was designed for a range of $\mathrm{Fe}$ (II) concentrations (from 1 to $300 \mathrm{mg} \mathrm{L}^{-1}$ ). An $\mathrm{Fe}$ spiking solution of $1000 \mathrm{mg} \mathrm{L}^{-1}$ $\mathrm{Fe}(\mathrm{II})$ was prepared with $\mathrm{FeSO}_{4}\left(\mathrm{H}_{2} \mathrm{O}\right)_{7}$, following Poulin et al. (2014), using the DOM stock solution so that spiking with $\mathrm{Fe}$ (II) would not change the overall concentration of DOM. Experiments were performed by sequentially adding $\mathrm{Fe}$ (II) spiking solution to an initial volume of $250 \mathrm{~mL}$ of DOM stock solution to reach 10 different concentrations between 1.3 to $306 \mathrm{mg} \mathrm{L}^{-1}$. Previous analyses of water from W3-14 via ICP-OES (inductively coupled plasma optical emission spectrometry) (Jia, 2015) indicated that the $\mathrm{SO}_{4}^{2-}$ concentration was $71 \mathrm{mg} \mathrm{L}^{-1}$ and that the $\mathrm{Cl}^{-}$concentration was $1670 \mathrm{mg} \mathrm{L}^{-1}$. Therefore, as the $\mathrm{Fe}(\mathrm{II})$ concentration was increased by a factor of 240 (from 1.3 to $306 \mathrm{mg} \mathrm{L}^{-1}$ ), the $\mathrm{SO}_{4}^{2-}$ concentration only increased by a factor of 8 (from approximately 71 to $595 \mathrm{mg} \mathrm{L}^{-1}$ ). We therefore expect that the dominant effect observed through this addition experiment is the effect of increasing $\mathrm{Fe}(\mathrm{II})$ rather than the effect of increasing $\mathrm{SO}_{4}^{2-}$ and/or total anions. The anion and cation con- centrations in the experimental spiked solution were similar to the natural conditions occurring in the aquifer. For example, for the depths with $\mathrm{Fe}^{2+}$ from $50-435 \mathrm{mg} \mathrm{L}^{-1}$, the range in $\mathrm{SO}_{4}^{2-}$ was $13-600 \mathrm{mgL}^{-1}$, and the range in $\mathrm{Cl}^{-}$was $50-$ $9600 \mathrm{mg} \mathrm{L}^{-1}$ (Jia, 2015).

If necessary, the $\mathrm{pH}$ of the experimental solution was adjusted using $0.1 \mathrm{M} \mathrm{NaOH}$ or $0.1 \mathrm{M} \mathrm{HCl}$ (to $7.4 \pm 0.3$ ) to match the target $\mathrm{pH}$ (7.44) of the original DOM stock solution. After each $\mathrm{Fe}(\mathrm{II})$ addition, $10 \mathrm{~mL}$ of the Fe(II) solution was pipetted into each of two glass cuvettes. One cuvette was acidified with concentrated $\mathrm{HCl}$ to a $\mathrm{pH}$ of approximately 2 and used to determine the total dissolved Fe(II), using a $\mathrm{HACH}^{\mathrm{TM}} \mathrm{DR} / 2010$ spectrophotometer via the colorimetric method (HACH ferrozine method) (Stookey, 1970). The cuvette of Fe(II) solution used for fluorescence analysis was capped tightly and transferred out of the glovebox for immediate analysis (Sect. 3.3).

\subsection{Fluorescence data acquisition and analysis}

The fluorescence analysis and the PARAFAC modelling were described by Ishii and Boyer (2012). All fluorescence spectra were obtained by using a Horiba Aqualog ${ }^{\circledR}$ (Horiba Scientific, Edison, NJ, USA) spectrofluorometer, equipped with subtractive double excitation monochromators (Hansen et al., 2018). A $150 \mathrm{~W}$ ozone-free vertically mounted xenon arc lamp was used as the excitation source. Both excitation and emission were collected at a bandpass of $5 \mathrm{~nm}$. Fluorescence intensities, as a function of the excitation and emission wavelengths, were measured across excitation wavelengths ranging from 240 to $800 \mathrm{~nm}$ in $3 \mathrm{~nm}$ increments; emission wavelengths, ranging from 250 to $830 \mathrm{~nm}$, were measured over an integration time of $0.1 \mathrm{~s}$. Water samples were analysed in $1 \mathrm{~cm}$ quartz cuvettes. Between the samples, the quartz cuvette was rinsed three times with Milli-Q water, followed by three times with the sample, to reduce possible crosscontamination. If necessary, water samples were quantitatively diluted with Milli-Q water until the UV absorbance was lower than 0.2 units (at $254 \mathrm{~nm}$ ) to minimize inner filter effects between the Milli-Q water and the water samples. The EEM spectra for each sample were obtained by subtracting the Milli-Q (blank) spectra to eliminate the Rayleigh scatter and water Raman peak (Murphy, 2011). Fluorescence intensity within all EEM data is presented in Raman units (RU) due to the way that raw EEM spectra are corrected prior to analysis via PARAFAC modelling or calculation of associated indices. As per standard practice, raw EEMs were instrument corrected via software provided by the instrument manufacturer. Spectra were corrected for inner filter effects (Ohno, 2002) and then normalized to the area under the Raman curve (Nieke et al., 1997; Stedmon et al., 2003); secondorder Raleigh scatter and Raman bands were excised at a bandpass of $12 \mathrm{~nm}$ (Bahram et al., 2006; Zepp et al., 2004), while first-order Raleigh scatter was excised at a bandwidth of $50 \mathrm{~nm}$ to remove all spectral artefacts (Bro, 1997; Stedmon 
and Bro, 2008). Specifically, normalization to the area under the Raman curve (which occurs due to the inelastic scatter of light by water) contributes to instrument correction that allows for the comparison of spectra between different instruments and thus different studies. The overall fluorescence intensity (OFI) was determined for each sample by adding the fluorescence intensities across all EEMs (Poulin et al., 2014). The relative fluorescence $\left(\mathrm{OFI} / \mathrm{OFI}_{0}\right)$ can be used to quantitatively determine the quenching effect of $\mathrm{Fe}(\mathrm{II})$ (Poulin et al., 2014), where OFI and $\mathrm{OFI}_{0}$ represent the Fe(II) addition samples and the original groundwater sample, respectively. Similarly, the intensity of the primary peak (peak A), at an excitation wavelength of $239 \mathrm{~nm}$, and at broad emission wavelengths ranging from 380 to $460 \mathrm{~nm}$, was determined for each sample, and the parameter $\mathrm{A} / \mathrm{A}_{0}$ was used to quantify the $\mathrm{Fe}(\mathrm{II})$ quenching effect on this diagnostic peak.

The established 13-component PARAFAC model of Cory and McKnight (2005) was used to fit the EEM spectra within this study. The 13 components consist of seven quinone-like fluorophores, including three oxidized quinones $(\mathrm{Q} 1, \mathrm{Q} 2$, and Q3), four reduced quinones (SQ1, SQ2, SQ3, and HQ), two amino acid-like components (tryptophan and tyrosine), and four remaining unknown fluorophores (Cory and McKnight, 2005). We chose to use this robust pre-resolved model, which was developed using DOM from a wide range of aquatic environments and has been subsequently applied to interpret EEMs from a large variety of aquatic systems (Jaffé et al., 2008; Larsen et al., 2010); see Sect. 3.3 for further details. The use of this 13-component model also facilitates the derivation of the redox index (RI), calculated by summing the reduced quinone-like inputs over total quinone-like inputs from components within the model. Finally, derivation of a unique, site-specific PARAFAC model typically requires a large sample set composed of samples from a common organic matter context (Cory and McKnight, 2005; Ishii and Boyer, 2012). As the aim of this study was to capture how spectral attributes are quenched upon addition of Fe(II) rather than characterization of the underlying organic matter properties, the application of a pre-resolved model ensures that model fitting is not biased by $\mathrm{Fe}(\mathrm{II})$ addition.

To ensure that this 13-component model adequately represented the fluorescent organic matter characteristics within the sample set, the residual fluorescence remaining after the model was applied was plotted and analysed. No systematic residuals were found after fitting the EEMs to the PARAFAC model, suggesting that the model was able to represent the samples and that $\mathrm{Fe}$ (II) additions did not significantly change the structure of fluorophores in the groundwater stock solution from the Kidd 2 site. The abundance of each fluorophore was quantified based on its relative contribution (\%) to the total fluorescence. Additionally, commonly used fluorescence indices, including fluorescence index (FI) (Cory and McKnight, 2005), humification index (HIX) (Ohno, 2002; Parlanti et al., 2000), the redox index (RI) (Miller et al., 2006), and freshness index (FrI, $\beta / \alpha$ ) (Parlanti et al., 2000; Zsolnay et al., 1999) were also quantified to provide further DOM characterization (Sect. 4.1.3). The dataset from this study is available on Zenodo (Jia et al., 2020).

\section{Results}

\subsection{The effect of Fe(II) quenching on EEM fluorescence}

\subsubsection{Relative fluorescence intensity $\left(\mathrm{OFI} / \mathrm{OFI}_{0}\right)$}

Figure 3 shows that the fluorescence intensities of EEMs decrease with increasing $\mathrm{Fe}(\mathrm{II})$, indicating that the DOM fluorescence of the groundwater stock solution collected from the Kidd 2 site was quenched by the addition of Fe(II). Figure $4 \mathrm{a}$ presents the decrease in the relative fluorescence intensity $\left(\mathrm{OFI} / \mathrm{OFI}_{0}\right)$ as $\mathrm{Fe}(\mathrm{II})$ increases from 1 to $306 \mathrm{mg} \mathrm{L}^{-1}$. Approximately $60 \%$ of the fluorescence intensity found in the $1 \mathrm{mgL}^{-1} \mathrm{Fe}$ (II) experimental solution was quenched in the $306 \mathrm{mg} \mathrm{L}^{-1} \mathrm{Fe}(\mathrm{II})$ experimental solution. The fluorescence intensity decreased more rapidly at lower $\mathrm{Fe}(\mathrm{II})$ concentrations: as $\mathrm{Fe}$ (II) increased from 1 to $101 \mathrm{mgL}^{-1}$ the OFI decreased by $\sim 40 \%$ and as $\mathrm{Fe}(\mathrm{II})$ increased from 101 to $306 \mathrm{mg} \mathrm{L}^{-1}$ the OFI decreased by an additional $\sim 20 \%$. The magnitude of quenching effect was more pronounced in this study than that performed by Poulin et al. (2014), who observed nonlinear fluorescence quenching ( $7 \%$ to $23 \%$ ) in four different surface water samples, by addition of $\mathrm{Fe}$ (II) up to $1.5 \mathrm{mg} \mathrm{L}^{-1}$, significantly lower than the $\mathrm{Fe}(\mathrm{II})$ concentrations used in this study.

$\mathrm{Fe}$ (III) also interacts with DOM and quenches fluorescence intensities (Ohno et al., 2008; Poulin et al., 2014). In this experiment, it was expected that some portion of $\mathrm{Fe}(\mathrm{II})$ would have oxidized to Fe(III) since the samples were directly exposed to the atmosphere when they were transferred to the sample cuvette for analysis. Nevertheless, the oxidation from $\mathrm{Fe}$ (II) to $\mathrm{Fe}$ (III) was limited due to the minimal exposure, and no visible Fe(III) colloids were observed prior to the analysis. The analysis took about 5-10 min for each sample; the full analysis was completed within an hour. Therefore, the quenching effect was unlikely to be caused by dynamic colloid formation. Furthermore, Poulin et al. (2014) found that almost no quenching was observed by $\mathrm{Fe}(\mathrm{III})$ from the oxidation of $\mathrm{Fe}$ (II) to $\mathrm{Fe}$ (III) at $\mathrm{pH}$ 6.7. Hence, the quenching effect in this experiment was believed to be primarily due to $\mathrm{Fe}$ (II)-DOM interactions.

\subsubsection{Relative peak-A fluorescence intensity $\left(A / A_{0}\right)$}

Many studies have characterized fluorescence properties of waters based on the primary peaks in EEM spectra, identified by visual inspection and/or multivariate data analysis (Chen et al., 2003; McKnight et al., 2001; Murphy et al., 2013; Shen et al., 2020; Stedmon et al., 2003; Stedmon and Bro, 2008). The positions of these peaks are believed to be linked to the organic matter properties. Coble $(1996 ; 1990)$ identi- 

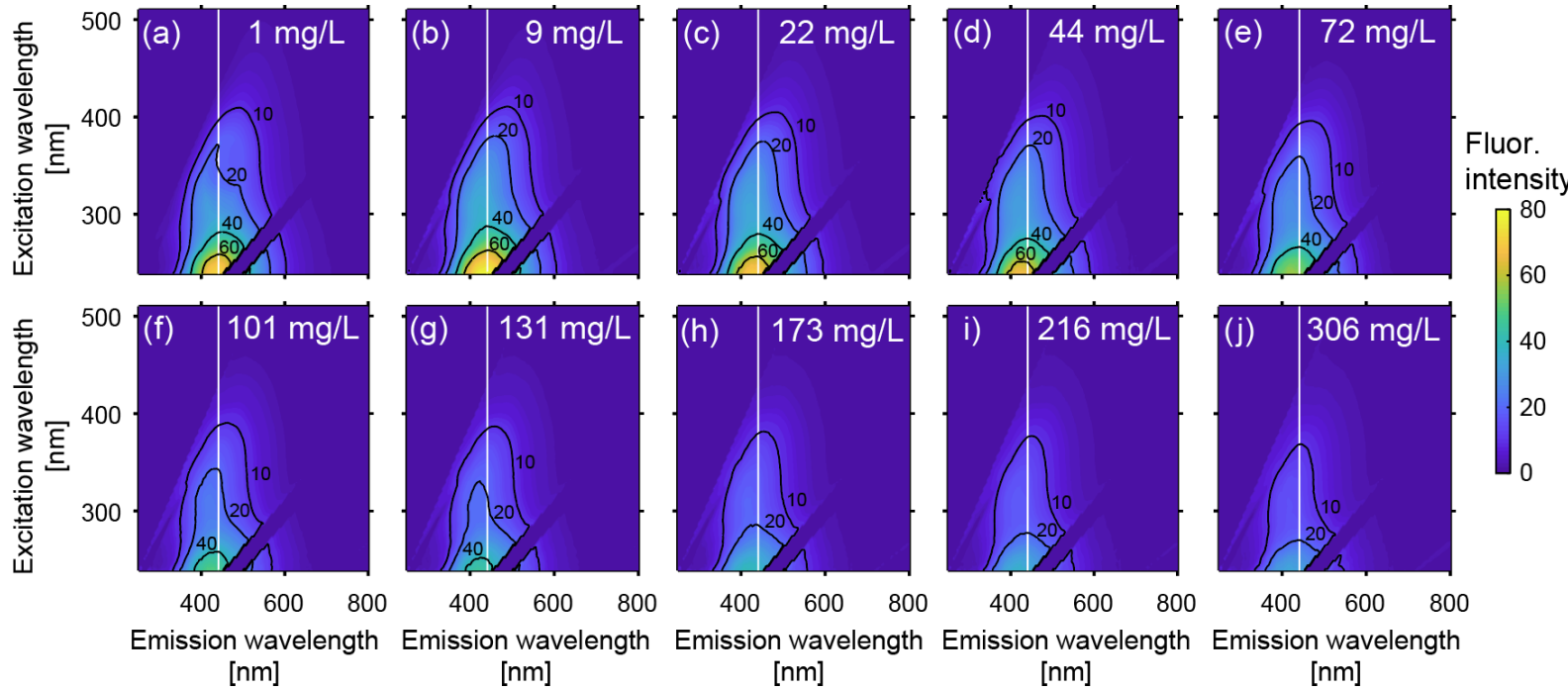

Figure 3. Excitation-emission matrices (EEMs) of groundwater from Fraser River aquifer over a range of Fe(II) concentrations. The Fe(II) concentration for each sample is indicated in $\mathrm{mg} \mathrm{L}^{-1}$ in the top right of each plot, from (a) $1 \mathrm{mgL}^{-1}$ to (j) to $306 \mathrm{mg} \mathrm{L}^{-1}$. To distinguish changes in the centre of the primary peak (peak A), a vertical dashed line at an emission wavelength of 441 nm is shown (the peak emission wavelength at excitation $239 \mathrm{~nm}$ for the $1 \mathrm{mgL}^{-1}$ solution; see Fig. 4). The fluorescence intensities are reported in Raman units (RU).

fied five primary peaks from a visual inspection of EEMs, including humic-like peaks $\mathrm{A}, \mathrm{C}$, and $\mathrm{M}$ and protein-like peaks $\mathrm{B}$ and $\mathrm{T}$. We observed only one distinct humic-like fluorescence peak (peak A) in the EEMs from W3-14. Peak A was in the UV region at an excitation wavelength of $239 \mathrm{~nm}$ and at broad emission wavelengths ranging from 380 to $460 \mathrm{~nm}$.

Similar to the trend observed for relative OFI (Sect. 4.1.1), the relative intensity of peak $A$ decreased by $\sim 60 \%$ as $\mathrm{Fe}$ (II) increased from 1 to $306 \mathrm{mgL}^{-1}$, and over $65 \%$ of the quenching occurred below $\mathrm{Fe}$ (II) concentrations of $101 \mathrm{mgL}^{-1}$ (Fig. 4c). In addition, the position of peak A continuously migrated towards the shorter (i.e., higher energy) emission wavelengths with a constant excitation wavelength of $239 \mathrm{~nm}$ and increasing Fe(II) concentration. Figure $4 \mathrm{e}$ presents the emission positions of peak $\mathrm{A}$ along with $\mathrm{Fe}(\mathrm{II})$ concentrations at excitation $239 \mathrm{~nm}$. Although a linear relationship was not observed, overall the location of fluorescence response gradually changed from 441 to $409 \mathrm{~nm}$ as $\mathrm{Fe}(\mathrm{II})$ increased from 1 to $306 \mathrm{mg} \mathrm{L}^{-1}$. This result is consistent with quenching experiments conducted with Everglades F1 water samples, where Poulin et al. (2014) observed a distinct shift in the quenching locations with increasing ratio of Fe(II) to DOM.

\subsubsection{Fluorescence intensities}

Iron quenching also affects several indices that are used to quantify DOM fluorescence properties. The most common indices are the fluorescence index (FI) (Cory and McKnight, 2005), humification index (HIX) (Parlanti et al., 2000; Ohno, 2002), the redox index (RI) (Miller et al., 2006), and freshness index $(\beta / \alpha)$ (Zsolnay et al., 1999; Parlanti et al., 2000).
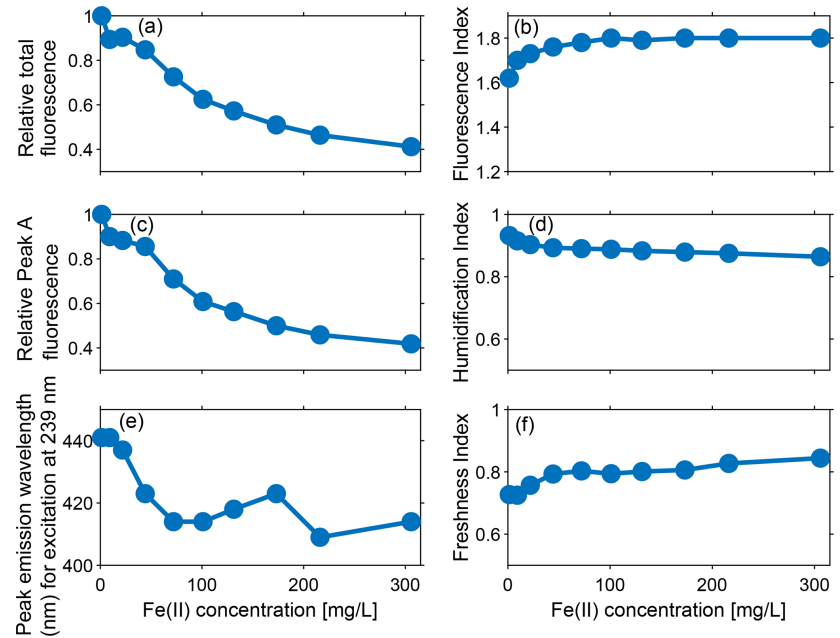

Figure 4. Effect of varying $\mathrm{Fe}(\mathrm{II})$ concentrations at $\mathrm{pH} 7.4$ on (a) relative total fluorescence intensity $\left(\mathrm{OFI} / \mathrm{OFI}_{0}\right)$, (c) relative fluorescence intensity of peak $\mathrm{A}\left(\mathrm{A} / \mathrm{A}_{0}\right)$, and (e) peak fluorescence emission wavelength (nm) at excitation at $239 \mathrm{~nm}$ (peak A). Effect of varying $\mathrm{Fe}(\mathrm{II})$ concentration at $\mathrm{pH} 7.4$ on various indices: (b) fluorescence index (FI), (d) humidification index (HIX), and (f) freshness index (FrI). The results show that the fluorescence intensities, indices, and peak emission wavelength change as $\mathrm{Fe}(\mathrm{II})$ is increased from 1 to $306 \mathrm{mg} \mathrm{L}^{-1}$. 
By defining the ratios of fluorescence intensity in different regions of the EEMs, indices can provide insight into the source of DOM, the degree of humification, and the relative age of the recently produced DOM.

The fluorescence index (FI) is the most widely used index that provides information about the source of organic matter. FI is defined using instrument-corrected spectra as the ratio of emission measured at $470 \mathrm{~nm}$ to that measured at $520 \mathrm{~nm}$, both from an excitation of $370 \mathrm{~nm}$ (Cory and McKnight, 2005). In the absence of fluorescence quenching by other dissolved constituents, high values of FI (approximately 1.80) indicate that DOM is derived from extracellular microbial activity, whereas low values of FI (approximately 1.20) suggest that DOM comes from terrestrial plant and soil organic matter (Cory and McKnight, 2005).

Measured FI values increased from an initial 1.62 to $1.80(\Delta \mathrm{FI}=+0.18 \mathrm{FI}$ units $)$ with increased $\mathrm{Fe}(\mathrm{II})$ concentrations (Fig. 4b), indicating the susceptibility of FI to the iron-quenching effect. As FI is a ratio of emission intensities, nonuniform changes in component emissions are responsible for the increase in FI values with $\mathrm{Fe}(\mathrm{II})$. Nevertheless, the effects of iron quenching on DOM fluorescence and FI were only observed in the 1 to $101 \mathrm{mg} \mathrm{L}^{-1}$ $\mathrm{Fe}$ (II) concentration range. As the $\mathrm{Fe}(\mathrm{II})$ increased from 101 to $306 \mathrm{mg} \mathrm{L}^{-1}$, the measured FI remained stable at $\sim 1.80$. Poulin et al. (2014) also observed that FI values increased more rapidly at low $\mathrm{Fe}(\mathrm{II})$ concentrations and began levelling off approaching the maximum $\mathrm{Fe}$ (II) concentrations that they studied $\left(1.5 \mathrm{mg} \mathrm{L}^{-1}\right)$. A stable value of FI was not reached in Poulin et al. (2014) for the Fe(II) addition experiment, probably because $1.5 \mathrm{mg} \mathrm{L}^{-1}$ of added $\mathrm{Fe}$ (II) did not saturate all available DOM ligands.

The humidification index (HIX) is defined as the peak area under the emission spectra from $435-480 \mathrm{~nm}$, divided by the peak area from $300-345 \mathrm{~nm}$ plus $435-480 \mathrm{~nm}$, at an excitation of $254 \mathrm{~nm}$ and typically ranges from $0-1$ (Ohno, 2002). Higher values of HIX (closer to 1) indicate greater humic content and extent of humidification. HIX values decreased with the addition of $\mathrm{Fe}(\mathrm{II})$ (from about 0.93 to 0.84 ), indicating that the emission spectra of fluorescence shifted towards shorter wavelengths (Fig. 4d). Moreover, the decrease in HIX occurred in two phases with increasing Fe(II), as represented by a change in slope. The steeper decrease of approximately $4.5 \%$ in HIX was observed as the $\mathrm{Fe}(\mathrm{II})$ concentration changed from 1 to $72 \mathrm{mgL}^{-1}$. Above $72 \mathrm{mg} \mathrm{L}^{-1}$ $\mathrm{Fe}(\mathrm{II})$, HIX only decreased $2.9 \%$. The results indicated that changes in emission spectra were therefore more sensitive to relatively low $\mathrm{Fe}(\mathrm{II})$ concentrations.

The freshness index (FrI or $\beta / \alpha$ ) is defined as the ratio of emission at $380 \mathrm{~nm}(\beta)$ divided by maximum emission between 420 and $435 \mathrm{~nm}(\alpha)$, all at an excitation of $310 \mathrm{~nm}$ (Parlanti et al., 2000; Wilson and Xenopoulos, 2009). It is a measure of the proportion of recently produced DOM, where $\beta$ represents freshly produced DOM, and $\alpha$ represents more decomposed DOM (Parlanti et al., 2000; Wilson
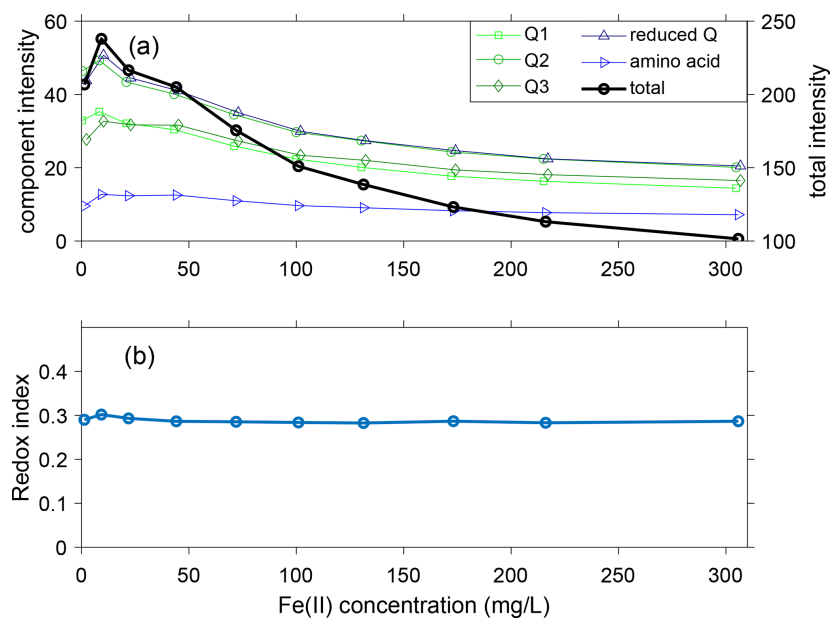

Figure 5. (a) Intensity of components at varying Fe quantities including quinones Q1, Q2, and Q3 (green); reduced quinones (reduced Q, calculated as the sum of SQ1, SQ2, SQ3, and HQ); amino acid (tryptophan and tyrosine); and total intensity; (b) redox index (RI) in the presence of varying $\mathrm{Fe}$ (II) quantities. In (a) the Fe concentrations have been slightly offset to better show overlapping symbols.

and Xenopoulos, 2009). A higher FrI indicates more recently created DOM, with values $>1$ indicating freshly released DOM and lower values $(0.6-0.7)$ corresponding to older DOM with a predominantly terrestrial source (Parlanti et al., 2000). Overall, the freshness index ranged between 0.72 to 0.84 and increased with $\mathrm{Fe}(\mathrm{II})$, except for the slight decrease seen at the Fe(II) concentration of $101 \mathrm{mg} \mathrm{L}^{-1}$ (Fig. 4f). Similar to the trend observed for HIX, the more rapid change of $10.4 \%$ occurred as the $\mathrm{Fe}$ (II) concentration ranged from 1 to $72 \mathrm{mg} \mathrm{L}^{-1}$ and a more gradual change of $6.3 \%$ occurred as the $\mathrm{Fe}(\mathrm{II})$ concentration ranged between 72 and $306 \mathrm{mg} \mathrm{L}^{-1}$.

\subsection{The effect of Fe(II) quenching on PARAFAC modelling and component distribution}

Of the 13 components identified by Cory and McKnight (2005), 7 components were identified as quinone-like organic components (including three oxidized quinones, Q1, Q2, and Q3, and four reduced quinones, SQ1, SQ2, SQ3, and $\mathrm{HQ}$ ), based on the similarity of the positions and relative intensities of the component excitation peaks compared to the absorbance and excitation peaks of model quinones. Two components were defined as resembling amino acid fluorophores ( $\mathrm{C} 8$, tryptophan, and $\mathrm{C} 13$, tyrosine). The remaining four components $(\mathrm{C} 1, \mathrm{C} 3, \mathrm{C} 6$, and $\mathrm{C} 10)$ have not been associated with any class of molecule. The three most abundant components were Q1, Q2, and Q3; together they contributed $49 \%-52 \%$ to the total fluorescence (Fig. 5). The excitation and emission spectra of the 13 components are included in our dataset published on Zenodo. 
The fluorescence intensity of each component peaked from 1 to $44 \mathrm{mg} \mathrm{L}^{-1} \mathrm{Fe}$ (II) and then steadily decreased as $\mathrm{Fe}$ (II) increased to $306 \mathrm{mgL}^{-1}$ (Fig. 5a). For all components except tryptophan (C8), the fluorescence at $306 \mathrm{mg} \mathrm{L}^{-1}$ $\mathrm{Fe}$ (II) was less than the fluorescence at $1 \mathrm{mgL}^{-1} \mathrm{Fe}$. As $\mathrm{Fe}$ (II) increased from 1 to $306 \mathrm{mg} \mathrm{L}^{-1}$, the total fluorescence intensity of the 13 components decreased by approximately $50 \%$, from 207 to $101 \mathrm{RU}$. However, the relative proportions of the components were relatively stable. The maximum deviation was seen in C6 (unknown classification), which decreased in relative proportion from $9 \%$ to $5 \%$ as $\mathrm{Fe}(\mathrm{II})$ increased from 1 to $306 \mathrm{mg} \mathrm{L}^{-1}$. For the other components, the changes in proportions were restricted to be within $\pm 3 \%$. We conclude that the proportions of the 13 components are relatively insensitive to the $\mathrm{Fe}(\mathrm{II})$ concentration for the DOM in the experimental stock solution from the Kidd 2 site.

The trends in component distribution can be further evaluated using the redox index (RI), which is calculated as the sum of reduced quinone-like inputs over the total quinonelike input. RI measures the oxidation state of the DOM and redox reactivities (Miller et al., 2006; Mladenov et al., 2008). The RI can be used to determine whether the quinone-like components within the DOM are more reduced (RI closer to 1) or more oxidized (RI closer to 0). A shift in the RI usually indicates changes in the redox status. The total oxidized (Q1, Q2, and Q3) and reduced (SQ1, SQ2, SQ3, and HQ) quinones changed their contributions to total fluorescence from $52 \%$ to $50 \%$ and from $21 \%$ to $20 \%$, respectively. The small changes for both oxidized and reduced quinones are responsible for the relatively stable values of RI, which slightly decreased from 0.30 to $\sim 0.285$ (Fig. 5b).

\section{Discussion}

Ferrous iron is responsible for the observed quenching of DOM fluorescence. Both the total fluorescence intensity of EEMs and peak-A intensity decreased with increasing Fe(II). The likely mechanism accounting for the quenching is complexation of $\mathrm{Fe}$ (II) with the fluorescent sites, efficiently decreasing the fluorescence intensity of fluorophores (Waite and Morel, 1984; Senesi, 1990). The nonlinear quenching of the fluorescence intensity with $\mathrm{Fe}$ (II) suggests, following Senesi (1990), a static quenching mechanism. However, our experiment does not allow us to identify quenching mechanisms. While the maximum ratio of $\mathrm{Fe}$ (II) to DOM (mg L $\mathrm{m}^{-1}$ per $\mathrm{mg}^{-1}$ ) was approximately 0.4 in Poulin et al. (2014), it is much larger in our study, with a molar Fe-to-C (as DOC) ratio of approximately 7 . While earlier work by Senesi (1990) suggests that quenching primarily depends upon the fraction of DOM ligands that is complexed to Fe(II), our study, with a great excess of $\mathrm{Fe}(\mathrm{II})$ over $\mathrm{C}$ in DOM, could involve other mechanisms. Poulin et al. (2014) found that $\mathrm{Fe}$ (II) quenching of fluorescence ranged from $7 \%$ to $23 \%$ in four different hydrophobic acid (HPOA) fractions and surface water samples, with DOC concentrations ranging from 2.3 to $5.0 \mathrm{mg} \mathrm{L}^{-1}$, and where the degree of quenching was not related to DOM concentrations. In our study, both total fluorescence intensity and peak-A intensity decreased by approximately $60 \%$ as $\mathrm{Fe}$ (II) increased from 1 to $306 \mathrm{mgL}^{-1}$. The differences in the impact of $\mathrm{Fe}$ (II) on fluorescence quenching between the representative groundwater from Kidd 2 site and those reported by Poulin et al. (2014) could be related to the much higher $\mathrm{Fe}(\mathrm{II})$ background in the organic-rich aquifer and groundwater at the Kidd 2 site. It should be noted that the DOC concentration in the Kidd 2 groundwater was $10.7 \mathrm{mg} \mathrm{L}^{-1}$, which is significantly greater than that in the previous study (Poulin et al., 2014).

Poulin et al. (2014) mainly examined the effect of Fe(II) addition to terrestrial-derived fresh surface water with undetectable Fe(II) levels. In contrast, the DOM in the stock solution collected from the Kidd 2 site is hypothesized to be derived from microbial sources and may respond to high $\mathrm{Fe}(\mathrm{II})$ concentrations differently than freshwater terrestrial-derived DOM. The quenching mechanism for this DOM is not well understood. Similar metal quenching of humic-like peaks has been observed by other researchers. Ohno et al. (2008) conducted experiments on the impact of $\mathrm{Fe}(\mathrm{III})$ and $\mathrm{Al}(\mathrm{III})$ addition to the deciduous water-soluble organic matter (WSOM) fluorescence spectra. This result showed that the fluorescence intensity was quenched by about $30 \%$ in the presence of $25 \mu \mathrm{M}\left(1.4 \mathrm{mg} \mathrm{L}^{-1}\right) \mathrm{Fe}$ for peak A (Ohno et al., 2008).

The fluorescence indices FI, HIX, and $\beta / \alpha$ provided evidence of the susceptibility to $\mathrm{Fe}(\mathrm{II})$ quenching, while RI was relatively insensitive to $\mathrm{Fe}$ (II) concentration. FI values increased by approximately 0.18 units from the addition of $300 \mathrm{mg} \mathrm{L}^{-1}$ of $\mathrm{Fe}$ (II) and shifted towards a greater microbialderived origin. This relatively small change may not affect the utility of FI towards inferring DOM origin. Moreover, FI values are more sensitive at low $\mathrm{Fe}$ (II) concentrations, and they gradually reach a plateau once $\mathrm{Fe}(\mathrm{II})$ is above $101 \mathrm{mg} \mathrm{L}^{-1}$, as all available DOM ligand sites are likely fully occupied by $\mathrm{Fe}(\mathrm{II})-\mathrm{DOM}$ interactions. This result also supports a static quenching mechanism, since quenching does not depend on the Fe(II) concentration (Senesi, 1990). Similar to FI, both HIX and $\beta / \alpha$ show more pronounced changes at low $\mathrm{Fe}$ (II) concentrations ( $\mathrm{Fe}(\mathrm{II})<72 \mathrm{mgL}^{-1}$ ). The decrease in HIX and increase of the $\beta / \alpha$ ratio are consistent, as they both indicate that the DOM shifted to more freshly produced, with a higher $\mathrm{H}: \mathrm{C}$ ratio and less polycondensation (Ohno, 2002). Nevertheless, the HIX and the $\beta / \alpha$ ratio are not likely to reach a constant value with $\mathrm{Fe}(\mathrm{II})$ concentration. Therefore, conclusions about organic matter origin based on humidification and freshness indices must consider the DOM sensitivity to Fe(II) concentration when reporting values.

In the 13-component PARAFAC model (Cory and McKnight, 2005), all components except $\mathrm{C} 8$ were quenched in terms of their fluorescence intensities. Nevertheless, changes in their "relative" component distribution were relatively 
small (within $\pm 4 \%$ contribution to total fluorescence). This result was consistent with the observation by Poulin et al. (2014), where changes in the component distributions were within $\pm 3 \%$ of the total fluorescence in their 13-component PARAFAC model. The small or negligible change in component distribution results in the relatively constant RI. Although few fluctuations were observed in the $\mathrm{Fe}(\mathrm{II})$ addition experiment, the overall trend of the RI is stable; thus, it can be used as a reliable index to infer the redox condition of the aquatic environment. Still, the component distribution may vary in different PARAFAC models. There were more pronounced distribution changes in a 7component model than in a 13-component model (Poulin et al., 2014). This suggests that the degree of quenching should always be associated with fluorophore classification. Besides fluorophore classification, DOM composition is another important factor that controls the quenching characterization. Ohno et al. (2008) found that quenching of fluorescence intensity varies depending on the DOM composition. In their three-component PARAFAC model, Fe(III) quenching was observed in all three components for the deciduous WSOM sample. For the coniferous WSOM sample, however, only components 1 and 2 were quenched, and component 3 increased slightly with the initial addition of Fe(III) and decreased with further Fe(III) additions.

While our study shows that high Fe(II) concentrations can influence fluorescence properties of a representative deltaic groundwater, it is difficult to generalize our results to other terrestrial waters with different DOM compositions without further analyses. We observed nonuniform quenching as a function of $\mathrm{Fe}$ concentration in this study, with smaller increases in quenching at concentrations above $100 \mathrm{~m} \mathrm{~L}^{-1}$. We note that both the DOM and Fe(II) concentrations that we examined were higher than those examined by Poulin et al. (2014).

\section{Summary}

This study demonstrates the quenching effect of $\mathrm{Fe}(\mathrm{II})$ in organic-rich anoxic groundwater from the Kidd 2 aquifer in the Fraser River Delta, Richmond, BC, where Fe(II) concentrations range from 1 to $300 \mathrm{mgL}^{-1}$ and the DOM concentration is $\sim 10 \mathrm{mg} \mathrm{L}^{-1}$. In our experiments, total fluorescence intensity decreased by approximately $60 \%$ as $\mathrm{Fe}(\mathrm{II})$ increased from 1 to $300 \mathrm{mg} \mathrm{L}^{-1}$. While our results are likely applicable to similar deltaic groundwaters, further analyses are required to quantify the quenching effect on fluorescence indices in other terrestrial waters (for example, surface waters with sufficiently high Fe concentrations such that quenching is likely). In this study, FI values tended to shift to be more autochthonous in origin with increasing Fe(II), but the small changes are unlikely to invalidate conclusions about the source of DOM. Changes in the humidification index and freshness index both indicated that the addition of
$\mathrm{Fe}(\mathrm{II})$ would shift these two indices towards more recently produced DOM. Therefore, the sensitivity of these indices should be evaluated when water samples contain Fe(II). The nonlinear relationship between the indices and $\mathrm{Fe}$ (II) can be seen in all of the indices, especially the FI. Although the intensities of all 13 components varied as a function of $\mathrm{Fe}(\mathrm{II})$, the relatively stable component distribution suggests that the $\mathrm{Fe}$ (II) quenching effect has a negligible effect on the 13component PARAFAC model. As a result, the PARAFAC model can be a reliable method for obtaining information about DOM composition in their relative distributions and redox status via the RI.

Code and data availability. The data presented in this article have been published on Zenodo at https://doi.org/10.5281/zenodo.3737108 (Jia et al., 2020).

Author contributions. $\mathrm{KJ}, \mathrm{AJ}$, and RDB designed experiments and $\mathrm{KJ}$ conducted experiments. $\mathrm{KJ}$ and $\mathrm{AJ}$ performed data analysis. $\mathrm{KJ}$ and CCMM prepared figures. CM compiled and archived the data. $\mathrm{KJ}$ and CCMM prepared the article with contributions from $\mathrm{AJ}$ and RDB.

Competing interests. The authors declare that they have no conflict of interest.

Disclaimer. Publisher's note: Copernicus Publications remains neutral with regard to jurisdictional claims in published maps and institutional affiliations.

Acknowledgements. We thank Mark Bolton for assistance with sample analysis and three anonymous reviewers for their helpful feedback that improved the article.

Financial support. This research has been supported by the NSERC (grant no. 121436-13).

Review statement. This paper was edited by Marnik Vanclooster and reviewed by three anonymous referees.

\section{References}

Aiken, G.: Fluorescence and Dissolved Organic Matter, in: Aquatic Organic Matter Fluorescence, edited by: Baker, A., Reynolds, D. M., Lead, J., Coble, P. G., and Spencer, R. G. M., Cambridge University Press, Cambridge, 35-74, https://doi.org/10.1017/CBO9781139045452.005, 2014.

Bahram, M., Bro, R., Stedmon, C., and Afkhami, A.: Handling of Rayleigh and Raman scatter for PARAFAC modeling of fluo- 
rescence data using interpolation, J. Chemometr., 20, 99-105, https://doi.org/10.1002/cem.978, 2006.

Baker, A. and Spencer, R. G. M.: Characterization of dissolved organic matter from source to sea using fluorescence and absorbance spectroscopy, Sci. Total Environ., 333, 217-232, https://doi.org/10.1016/j.scitotenv.2004.04.013, 2004.

Bolton, M. and Beckie, R.: Aqueous and mineralogical analysis of arsenic in the reduced, circumneutral groundwater and sediments of the lower Fraser River delta, British Columbia, Canada, Appl. Geochem., 26, 458-469, https://doi.org/10.1016/j.apgeochem.2011.01.005, 2011.

Bro, R.: PARAFAC. Tutorial and applications, Chemometr. Intell. Lab., 38, 149-171, https://doi.org/10.1016/S01697439(97)00032-4, 1997.

Chen, M., Price, R. M., Yamashita, Y., and Jaffé, R.: Comparative study of dissolved organic matter from groundwater and surface water in the Florida coastal Everglades using multi-dimensional spectrofluorometry combined with multivariate statistics, Appl. Geochem., 25, 872-880, https://doi.org/10.1016/j.apgeochem.2010.03.005, 2010.

Chen, W., Westerhoff, P., Leenheer, J. A., and Booksh, K.: Fluorescence Excitation-Emission Matrix Regional Integration to Quantify Spectra for Dissolved Organic Matter, Environ. Sci. Technol., 37, 5701-5710, https://doi.org/10.1021/es034354c, 2003.

Christensen, T. H., Kjeldsen, P., Bjerg, P. L., Jensen, D. L., Christensen, J. B., Baun, A., Albrechtsen, H.-J., and Heron, G.: Biogeochemistry of landfill leachate plumes, Appl. Geochem., 16, 659-718, https://doi.org/10.1016/S0883-2927(00)00082-2, 2001.

Coble, P. G.: Characterization of marine and terrestrial DOM in seawater using excitation-emission matrix spectroscopy, Mar. Chem., 51, 325-346, https://doi.org/10.1016/03044203(95)00062-3, 1996.

Coble, P. G., Green, S. A., Blough, N. V., and Gagosian, R. B.: Characterization of dissolved organic matter in the Black Sea by fluorescence spectroscopy, Nature, 348, 432-435, https://doi.org/10.1038/348432a0, 1990.

Coble, P. G., Lead, J., Baker, A., Reynolds, D. M., and Spencer, R. G. M.: Aquatic Organic Matter Fluorescence, Cambridge University Press, Cambridge, 407 pp., 2014.

Cory, R. M. and McKnight, D. M.: Fluorescence Spectroscopy Reveals Ubiquitous Presence of Oxidized and Reduced Quinones in Dissolved Organic Matter, Environ. Sci. Technol., 39, 81428149, https://doi.org/10.1021/es0506962, 2005.

Fellman, J. B., Hood, E., and Spencer, R. G. M.: Fluorescence spectroscopy opens new windows into dissolved organic matter dynamics in freshwater ecosystems: A review, Limnol. Oceanogr., 55, 2452-2462, https://doi.org/10.4319/lo.2010.55.6.2452, 2010.

Hansen, A. M., Fleck, J., Kraus, T. E. C., Downing, B. D., von Dessonneck, T., and Bergamaschi, B.: Procedures for using the Horiba Scientific Aqualog ${ }^{\circledR}$ fluorometer to measure absorbance and fluorescence from dissolved organic matter, Procedures for using the Horiba Scientific Aqualog ${ }^{\circledR}$ fluorometer to measure absorbance and fluorescence from dissolved organic matter, U.S. Geological Survey, Reston, VA, https://doi.org/10.3133/ofr20181096, 2018.

Harvey, C. F., Swartz, C. H., Badruzzaman, A. B. M., KeonBlute, N., Yu, W., Ali, M. A., Jay, J., Beckie, R., Niedan,
V., Brabander, D., Oates, P. M., Ashfaque, K. N., Islam, S., Hemond, H. F., and Ahmed, M. F.: Arsenic mobility and groundwater extraction in Bangladesh, Science, 298, 1602-1606, https://doi.org/10.1126/science.1076978, 2002.

Helms, J. R., Stubbins, A., Ritchie, J. D., Minor, E. C., Kieber, D. J., and Mopper, K.: Absorption spectral slopes and slope ratios as indicators of molecular weight, source, and photobleaching of chromophoric dissolved organic matter, Limnol. Oceanogr., 53, 955-969, https://doi.org/10.4319/1o.2008.53.3.0955, 2008.

Heron, G., Crouzet, C., Bourg, A. C. M., and Christensen, T. H.: Speciation Of $\mathrm{Fe}$ (Ii) And Fe(Iii) In Contaminated Aquifer Sediments Using Chemical-Extraction Techniques, Environ. Sci. Technol., 28, 1698-1705, 1994.

Hudson, N., Baker, A., and Reynolds, D.: Fluorescence analysis of dissolved organic matter in natural, waste and polluted waters - a review, River Res. Appl., 23, 631-649, https://doi.org/10.1002/rra.1005, 2007.

Ishii, S. K. L. and Boyer, T. H.: Behavior of Reoccurring PARAFAC Components in Fluorescent Dissolved Organic Matter in Natural and Engineered Systems: A Critical Review, Environ. Sci. Technol., 46, 2006-2017, 2012.

Jaffé, R., McKnight, D., Maie, N., Cory, R., McDowell, W. H., and Campbell, J. L.: Spatial and temporal variations in DOM composition in ecosystems: The importance of long-term monitoring of optical properties, J. Geophys. Res.-Biogeo., 113, G04032, https://doi.org/10.1029/2008JG000683, 2008.

Jaffé, R., Cawley, K. M., and Yamashita, Y.: Applications of Excitation Emission Matrix Fluorescence with Parallel Factor Analysis (EEM-PARAFAC) in Assessing Environmental Dynamics of Natural Dissolved Organic Matter (DOM) in Aquatic Environments: A Review, in: ACS Symposium Series, vol. 1160, edited by: Rosario-Ortiz, F., American Chemical Society, Washington, DC, 27-73, https://doi.org/10.1021/bk-2014-1160.ch003, 2014.

Jia, K.: Iron and manganese reduction driven by organic matter and mixing of fresh and saline groundwater in the Fraser River delta aquifer, University of British Columbia, Vancouver, Canada, https://doi.org/10.14288/1.0167190, 2015.

Jia, K., Manning, C. C., Jollymore, A., and Beckie, R. D.: Dataset for "Technical note: Effects of iron(II) on fluorescence properties of dissolved organic matter at circumneutral $\mathrm{pH}$," Zenodo [data set], https://doi.org/10.5281/zenodo.3737108, 2020.

Larsen, L. G., Aiken, G. R., Harvey, J. W., Noe, G. B., and Crimaldi, J. P.: Using fluorescence spectroscopy to trace seasonal DOM dynamics, disturbance effects, and hydrologic transport in the Florida Everglades, J. Geophys. Res.-Biogeo., 115, G03001, https://doi.org/10.1029/2009JG001140, 2010.

McKnight, D. M., Boyer, E. W., Westerhoff, P. K., Doran, P. T., Kulbe, T., and Andersen, D. T.: Spectrofluorometric characterization of dissolved organic matter for indication of precursor organic material and aromaticity, Limnol. Oceanogr., 46, 38-48, 2001.

Miller, M. P., McKnight, D. M., Cory, R. M., Williams, M. W., and Runkel, R. L.: Hyporheic Exchange and Fulvic Acid Redox Reactions in an Alpine Stream/Wetland Ecosystem, Colorado Front Range, Environ. Sci. Technol., 40, 5943-5949, https://doi.org/10.1021/es060635j, 2006.

Mladenov, N., Huntsman-Mapila, P., Wolski, P., Masamba, W. R. L., and McKnight, D. M.: Dissolved organic matter accumulation, reactivity, and redox state in 
ground water of a recharge wetland, Wetlands, 28, 747-759, https://doi.org/10.1672/07-140.1, 2008.

Murphy, K. R.: A Note on Determining the Extent of the Water Raman Peak in Fluorescence Spectroscopy, Appl. Spectrosc., 65, 233-236, https://doi.org/10.1366/10-06136, 2011.

Murphy, K. R., Stedmon, C. A., Graeber, D., and Bro, R.: Fluorescence spectroscopy and multi-way techniques. PARAFAC, Anal. Methods-UK, 5, 6557-6566, https://doi.org/10.1039/C3AY41160E, 2013.

Neilson-Welch, L. and Smith, L.: Saline water intrusion adjacent to the Fraser River, Richmond, British Columbia, Can. Geotech. J., 38, 67-82, 2001.

Nieke, B., Reuter, R., Heuermann, R., Wang, H., Babin, M., and Therriault, J. C.: Light absorption and fluorescence properties of chromophoric dissolved organic matter (CDOM), in the St. Lawrence Estuary (Case 2 waters), Cont. Shelf Res., 17, 235252, https://doi.org/10.1016/S0278-4343(96)00034-9, 1997.

Ohno, T.: Fluorescence Inner-Filtering Correction for Determining the Humification Index of Dissolved Organic Matter, Environ. Sci. Technol., 36, 742-746, https://doi.org/10.1021/es0155276, 2002.

Ohno, T., Amirbahman, A., and Bro, R.: Parallel Factor Analysis of Excitation-Emission Matrix Fluorescence Spectra of Water Soluble Soil Organic Matter as Basis for the Determination of Conditional Metal Binding Parameters, Environ. Sci. Technol., 42, 186-192, https://doi.org/10.1021/es071855f, 2008.

Parlanti, E., Wörz, K., Geoffroy, L., and Lamotte, M.: Dissolved organic matter fluorescence spectroscopy as a tool to estimate biological activity in a coastal zone submitted to anthropogenic inputs, Org. Geochem., 31, 1765-1781, https://doi.org/10.1016/S0146-6380(00)00124-8, 2000.

Poulin, B. A., Ryan, J. N., and Aiken, G. R.: Effects of Iron on Optical Properties of Dissolved Organic Matter, Environ. Sci. Technol., 48, 10098-10106, https://doi.org/10.1021/es502670r, 2014.

Pullin, M. J., Anthony, C., and Maurice, P. A.: Effects of Iron on the Molecular Weight Distribution, Light Absorption, and Fluorescence Properties of Natural Organic Matter, Environ. Eng. Sci., 24, 987-997, https://doi.org/10.1089/ees.2006.0040, 2007.

Rue, E. L. and Bruland, K. W.: Complexation of iron(III) by natural organic ligands in the Central North Pacific as determined by a new competitive ligand equilibration/adsorptive cathodic stripping voltammetric method, Mar. Chem., 50, 117-138, https://doi.org/10.1016/0304-4203(95)00031-L, 1995.

Senesi, N.: Molecular and quantitative aspects of the chemistry of fulvic acid and its interactions with metal ions and organic chemicals: Part II. The fluorescence spectroscopy approach, Anal. Chim. Acta, 232, 77-106, https://doi.org/10.1016/S00032670(00)81226-X, 1990.
Shen, J., Liu, B., Wu, J., Chai, Y., Cheng, C., Liu, C., Yan, R., and Saleem Khan, M. F.: Characterization of fluorescent dissolved organic matters in metalworking fluid by fluorescence excitation-emission matrix and highperformance liquid chromatography, Chemosphere, 239, 124703, https://doi.org/10.1016/j.chemosphere.2019.124703, 2020.

Stedmon, C. A. and Bro, R.: Characterizing dissolved organic matter fluorescence with parallel factor analysis: a tutorial, Limnol. Oceanogr.-Meth., 6, 572-579, https://doi.org/10.4319/lom.2008.6.572, 2008.

Stedmon, C. A., Markager, S., and Bro, R.: Tracing dissolved organic matter in aquatic environments using a new approach to fluorescence spectroscopy, Mar. Chem., 82, 239-254, https://doi.org/10.1016/S0304-4203(03)00072-0, 2003.

Stookey, L. L.: Ferrozine - a new spectrophotometric reagent for iron, Anal. Chem., 42, 779-781, https://doi.org/10.1021/ac60289a016, 1970.

van Breukelen, B. M. and Griffioen, J.: Biogeochemical processes at the fringe of a landfill leachate pollution plume: potential for dissolved organic carbon, $\mathrm{Fe}(\mathrm{II}), \mathrm{Mn}(\mathrm{II}), \mathrm{NH}_{4}$, and $\mathrm{CH}_{4}$ oxidation, J. Contam. Hydrol., 73, 181-205, https://doi.org/10.1016/j.jconhyd.2004.01.001, 2004.

Waite, T. D. and Morel, F. M. M.: Ligand exchange and fluorescence quenching studies of the fulvic acid-iron interaction: Effects of ph and light, Anal. Chim. Acta, 162, 263-274, https://doi.org/10.1016/S0003-2670(00)84247-6, 1984.

Weishaar, J. L., Aiken, G. R., Bergamaschi, B. A., Fram, M. S., Fujii, R., and Mopper, K.: Evaluation of specific ultraviolet absorbance as an indicator of the chemical composition and reactivity of dissolved organic carbon, Environ. Sci. Technol., 37, 47024708, https://doi.org/10.1021/es030360x, 2003.

Wilson, H. F. and Xenopoulos, M. A.: Effects of agricultural land use on the composition of fluvial dissolved organic matter, Nat. Geosci., 2, 37-41, https://doi.org/10.1038/ngeo391, 2009.

Zepp, R. G., Sheldon, W. M., and Moran, M. A.: Dissolved organic fluorophores in southeastern US coastal waters: correction method for eliminating Rayleigh and Raman scattering peaks in excitation-emission matrices, Mar. Chem., 89, 15-36, https://doi.org/10.1016/j.marchem.2004.02.006, 2004.

Zsolnay, A., Baigar, E., Jimenez, M., Steinweg, B., and Saccomandi, F.: Differentiating with fluorescence spectroscopy the sources of dissolved organic matter in soils subjected to drying, Chemosphere, 38, 45-50, https://doi.org/10.1016/S00456535(98)00166-0, 1999. 